\title{
Temperature dependence of the Brewer global UV measurements
}

\author{
Ilias Fountoulakis ${ }^{1}$, Alberto Redondas ${ }^{2}$, Kaisa Lakkala ${ }^{3,5}$, Alberto Berjon ${ }^{4}$, Alkiviadis F. Bais ${ }^{1}$, Lionel Doppler ${ }^{5}$, \\ Uwe Feister $^{5}$, Anu Heikkila ${ }^{6}$, Tomi Karppinen ${ }^{3}$, Juha M. Karhu ${ }^{3}$, Tapani Koskela ${ }^{6, a}$, Katerina Garane ${ }^{1}$, \\ Konstantinos Fragkos ${ }^{1,7}$, and Volodya Savastiouk ${ }^{8}$ \\ ${ }^{1}$ Aristotle University of Thessaloniki, Laboratory of Atmospheric Physics, Thessaloniki, Greece \\ ${ }^{2}$ Agencia Estatal de Meteorología, Izaña Atmospheric Research Center, Tenerife, Spain \\ ${ }^{3}$ Finnish Meteorological Institute - Arctic Research Centre, Sodankylä, Finland \\ ${ }^{4}$ Department of Industrial Engineering, University of La Laguna, Santa Cruz de Tenerife, Spain \\ ${ }^{5}$ Meteorologisches Observatorium Lindenberg - Richard Assmann Observatorium (DWD, MOL-RAO), \\ Deutscher Wetterdienst, Lindenberg, Germany \\ ${ }^{6}$ Climate Research, Finnish Meteorological Institute, Helsinki, Finland \\ ${ }^{7}$ National Institute of R\&D for Optoelectronics, Magurele, Romania \\ ${ }^{8}$ International Ozone Services Inc, Toronto, Canada \\ ${ }^{\text {a }}$ now independent researcher
}

Correspondence to: Alberto Redondas (aredondasm@aemet.es)

Received: 26 May 2017 - Discussion started: 20 June 2017

Revised: 18 October 2017 - Accepted: 19 October 2017 - Published: 22 November 2017

\begin{abstract}
Spectral measurements of global UV irradiance recorded by Brewer spectrophotometers can be significantly affected by instrument-specific optical and mechanical features. Thus, proper corrections are needed in order to reduce the associated uncertainties to within acceptable levels. The present study aims to contribute to the reduction of uncertainties originating from changes in the Brewer internal temperature, which affect the performance of the optical and electronic parts, and subsequently the response of the instrument. Until now, measurements of the irradiance from various types of lamps at different temperatures have been used to characterize the instruments' temperature dependence. The use of $50 \mathrm{~W}$ lamps was found to induce errors in the characterization due to changes in the transmissivity of the Teflon diffuser as it warms up by the heat of the lamp. In contrast, the use of 200 or $1000 \mathrm{~W}$ lamps is considered more appropriate because they are positioned at longer distances from the diffuser so that warming is negligible. Temperature gradients inside the instrument can cause mechanical stresses which can affect the instrument's optical characteristics. Therefore, during the temperature-dependence characterization procedure warming or cooling must be slow enough to minimize these effects. In this study, results of the temperature characterization of eight different Brewer spec-
\end{abstract}

trophotometers operating in Greece, Finland, Germany and Spain are presented. It was found that the instruments' response changes differently in different temperature regions due to different responses of the diffusers' transmittance. The temperature correction factors derived for the Brewer spectrophotometers operating at Thessaloniki, Greece, and Sodankylä, Finland, were evaluated and were found to remove the temperature dependence of the instruments' sensitivity.

\section{Introduction}

Brewer spectrophotometers were developed in the 1970s and became commercially available at the beginning of the $1980 \mathrm{~s}$ (Brewer, 1973; Kerr et al., 1985b). They were initially designed to measure the total columns of ozone $\left(\mathrm{O}_{3}\right)$ and sulfur dioxide $\left(\mathrm{SO}_{2}\right)$ and, towards the end of the $1980 \mathrm{~s}$, they were modified to perform also spectral measurements of the global solar UV irradiance (Kerr and McElroy, 1995; Bais et al., 1996). Nowadays, more than 200 Brewer spectrophotometers are deployed worldwide. Spectral UV measurements from Brewers were used in a number of important studies which highlighted the impact of the stratospheric ozone depletion until the mid-1990s on the levels of the solar UV- 
B irradiance that reaches the Earth surface (Fioletov et al., 2001; Kerr and McElroy, 1993; Lakkala et al., 2003; McKenzie et al., 1999) and quantified the interaction between the solar UV irradiance, the Earth surface and the atmospheric components which mainly control its levels, such as ozone, sulfur dioxide, aerosols and clouds (e.g., Arola et al., 2003; Bais et al., 1993; Bernhard et al., 2007; Fioletov et al., 1998). Spectral measurements from Brewers have been used widely for climatological studies of biologically effective UV doses (e.g., Fioletov et al., 2003, 2009; Kimlin, 2004), validation of satellite products (e.g., Arola et al., 2002; Bernhard et al., 2015; Kazadzis et al., 2009) and validation of radiative transfer models (Kazantzidis et al., 2001; Mayer et al., 1997). Lately, spectra from stations with long measurement records have been used for the study of the changes of the solar UV irradiance, showing that changes in air quality and climate have an important impact on its short- and long-term variability (De Bock et al., 2014; Fountoulakis et al., 2016a; Fragkos et al., 2016; Lakkala et al., 2017; Simic et al., 2011; Smedley et al., 2012; Zerefos et al., 2012).

The uncertainty in the measurements of the total ozone column (TOC) is considered to be low, of the order of $1 \%$ (Kerr et al., 1985a), while the uncertainty in the measurements of the global spectral UV irradiance for wavelengths greater than $305 \mathrm{~nm}$ is estimated to be less than $\sim 6.5 \%$ for well-maintained and calibrated instruments (Bernhard and Seckmeyer, 1999; Garane et al., 2006). However, insufficient correction for the effects of individual constructional and operational characteristics - e.g., stray light (Karppinen et al., 2014), dead time (Fountoulakis et al., 2016b), cosine response (Antón et al., 2008; Bais et al., 1998) and temperature dependence (Garane et al., 2006; Lakkala et al., 2008) may lead to even larger uncertainties (Gröbner et al., 2006). Thus, better understanding of the instrument's characteristics and improvement of the characterization methods are necessary for keeping the uncertainties within acceptable limits (Seckmeyer et al., 2001). Improvement of the quality of the spectra is also essential for the detection of trends in the time series of the measured irradiance (Weatherhead et al., 1998).

Changes in the internal temperature can affect the electronic, mechanical and optical parts, and subsequently the spectral response of each individual Brewer spectrophotometer (Kerr, 2010). They have multiple and complex effects on the spectral response of the Brewer spectrophotometers. Existing studies (e.g., Garane et al., 2006; Lakkala et al., 2008; Weatherhead et al., 2001) suggest that temperature mainly affects the response of the photomultiplier tube (PMT) and the transmittance of the $\mathrm{NiSO}_{4}$ filter used in the singlemonochromator Brewers. However, it is also possible that temperature affects the transmittance of the Teflon diffuser located at the entrance of the fore-optics (Ylianttila and Schreder, 2005) and also causes subtraction and contraction of the instruments' mechanical components which may affect their response. The characterization procedure (and the subsequent correction of the spectra for the effects of temper- ature) is quite difficult and uncertain for the following reasons: (1) different components of the instrument are affected differently by changes in temperature, (2) specific components (e.g., the PMT, the standard lamp or the heater) increase the temperature locally while they are operating, resulting in large temperature gradients inside the instrument, (3) the characterization conditions (e.g., warming and cooling rate) differ from the conditions during the instrument regular operation, (4) the lamps used for the characterization may warm the diffuser and (5) the effects of temperature depend on the individual characteristics of each instrument. Nevertheless, proper characterization is necessary in order to take the effects of temperature into account and avoid errors in the final products.

The present study is focused on the evaluation of the characterization and correction methods for the effects of temperature on the measurements of the global UV irradiance. Evaluation of the currently used methodology for the characterization and correction of the direct irradiance and TOC measurements is out of the scope of the present study. The internal temperature of the Brewer may change by up to about $20^{\circ} \mathrm{C}$ in a day and by $40-50^{\circ} \mathrm{C}$ in a year. Existing studies suggest that the absolute response of the instruments may change by $0.2-0.3 \%$ per $1{ }^{\circ} \mathrm{C}$ change of the internal temperature (Garane et al., 2006; Lakkala et al., 2008). Thus, not accounting for temperature effects may lead to uncertainties or biases greater than the desirable overall uncertainty in the measurements.

In contrast to the correction of TOC measurements for the effects of temperature, which is achieved using a standard methodology (Kipp \& Zonen, 2008; Savastiouk, 2005; SCITEC Instruments Inc., 1999), there is no standard method for the characterization or the correction of the Brewer global UV measurements. At several sites, 50, 200 and $1000 \mathrm{~W}$ tungsten halogen lamps, which are used to monitor the stability and/or calibrate the Brewer spectrophotometers (e.g., Bais et al., 1996; Bernhard et al., 2008; Heikkilä et al., 2016), are also used for the temperature characterization of the instruments. These lamps are usually warm-colored, with a color temperature of $\sim 3000 \mathrm{~K}$ - thus they emit a significant amount of infrared radiation. They are usually placed at vertical distances of $5, \sim 20$ and $50 \mathrm{~cm}$ from the diffuser, respectively, with the center of their filament aligned with the center of the diffuser. Measurements are performed either inside, or outdoors at the regular operating position of the instrument, using various setups which may differ between individual stations. In Cappellani and Kochler (2000), Siani et al. (2003) and Weatherhead et al. (2001) the temperature characterization of the global UV measurements was achieved by performing measurements of the irradiance from $50 \mathrm{~W}$ lamps outdoors, at different ambient temperatures. In two more recent studies (Garane et al., 2006; Lakkala et al., 2008) the reported temperature correction factors were derived by performing measurements with $1000 \mathrm{~W}$ lamps in the laboratory. Using the internal $20 \mathrm{~W}$ standard lamp (SL) 
(Kipp \& Zonen, 2008) for temperature characterization may lead to errors since the emissivity of the lamp may be affected by the temperature effects on the lamp's power supply (Weatherhead et al., 2001). Furthermore, when the SL is on, it is possible that large temperature gradients exist inside the instrument. In addition, any changes in the transmittance of the diffuser are not taken into account when the internal lamp is used. All the above studies have reported that the Brewer's response is a monotonic linear function of temperature which may also depend on wavelength. However, Ylianttila and Schreder (2005) found a sharp change in the transmittance of the polytetrafluoroethylene (commonly known as Teflon) diffusers near $19^{\circ} \mathrm{C}$, usually ranging from 1 to $3 \%$, which should also affect the response of Brewer spectrophotometers. This temperature behavior has not been confirmed so far for the diffusers used in Brewer spectrophotometers.

In the present study we investigate the effects on Brewer diffusers when 50, 200 and $1000 \mathrm{~W}$ tungsten halogen lamps are used for the characterization of the temperature dependence of spectral UV irradiance measurements. Additionally, the results of the characterization for the effects of temperature, the single-monochromator Brewer spectrophotometers with serial numbers 005, 030, 037, 078 (from now on referred to as B005, B030, B037, B078, respectively) and the doublemonochromator Brewer spectrophotometers with serial numbers 086, 107, 185 and 214 (from now on referred to as B086, B107, B185 and B214, respectively) are analyzed and compared to each other. These instruments are operating regularly at Thessaloniki, Greece (B005 and B086); Sodankylä, Finland (B037 and B214); Helsinki, Finland (B107); Lindenberg, Germany (B030 and B078); and Izaña, Tenerife, Spain (B185). Finally, the application of the derived temperature correction factors is evaluated for the Brewer spectrophotometers operating at Thessaloniki and Sodankylä.

\section{Evaluation of the temperature characterization with external lamps}

As listed in the Introduction, the temperature dependence can be due to different reasons. In this study, we investigated how the error due to the temperature dependence can be corrected using the only available information which a standard Brewer user has: the PMT temperature. We study which method is best to characterize the Brewer (50, 200, $1000 \mathrm{~W}$ lamps) and which uncertainties are related to this method. For this purpose measurements with 50 and $1000 \mathrm{~W}$ lamps were performed by B005, B086 and B214 inside the laboratory, while measurements with $200 \mathrm{~W}$ lamps were performed by B185 at the site of the instrument's regular operation.

Characterization of B214 with 50 and $1000 \mathrm{~W}$ lamps was performed using the methodology described in Lakkala et al. (2008). Measurements with both types of lamps were performed under the same conditions, so that any differences in

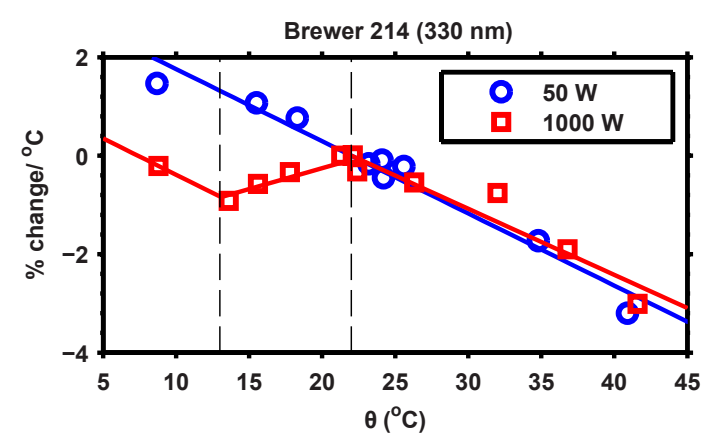

Figure 1. Changes in the response of B214 at $330 \mathrm{~nm}$, relative to the response at $25^{\circ} \mathrm{C}$ for the same wavelength, as a result of changes in temperature, derived using 50 and $1000 \mathrm{~W}$ tungsten halogen lamps.

the results could be attributed to effects of the used lamps. The change in the response of B214 at various temperatures relative to $25^{\circ} \mathrm{C}$ for $330 \mathrm{~nm}$ is presented in Fig. 1. While the results from the $50 \mathrm{~W}$ lamp indicate that the response of the Brewer decreases linearly with temperature, the $1000 \mathrm{~W}$ lamp reveals a sudden increase in the response for temperatures between $\sim 13$ and $22^{\circ} \mathrm{C}$, and for higher and lower temperatures the pattern is similar with the $50 \mathrm{~W}$ lamp. Similar results are obtained for all wavelengths. The characterization of B005 and B086 with 50 and $1000 \mathrm{~W}$ lamps yielded patterns which were also similar to those presented in Fig. 1. It should be noted that the characterization procedure followed for these two instruments (Garane et al., 2006) is slightly different compared to that of Lakkala et al. (2008).

The different behavior of the Brewer's temperature dependence could be attributed only to the different thermal effect of the two lamps on the diffuser, taking into account that although weaker, the $50 \mathrm{~W}$ lamps are placed much closer to the diffuser. In order to investigate this effect further, the temperature of the diffuser of the two Brewers operating at Thessaloniki was measured with a VOLTCRAFT IR 260-85 infrared thermometer while each lamp was turned on. The lamps were positioned at the same distances and with the same configuration as in the absolute calibration and the temperature characterization tests. Initially, only the cover of the Brewer that holds the diffuser with the dome was used and the temperature was measured by pointing the IR thermometer towards the center of the diffuser from beneath - i.e., from the side where normally the fore optics of the Brewer are located. The temperature of the diffuser was measured when it was not illuminated by the lamp. The lamp was either moved away ( $50 \mathrm{~W}$ lamps) or the radiation was blocked (1000 W lamps) before each measurement. This procedure was repeated several times for about $90 \mathrm{~min}$. During the test the ambient temperature in the vicinity of the diffuser was also monitored. The temperature of the diffuser and the ambient as a function of time are presented for B005 in Fig. 2a and $\mathrm{b}$, respectively, for the $50 \mathrm{~W}$ and the $1000 \mathrm{~W}$ lamps. The behavior of B086 is almost identical to that of B005. 


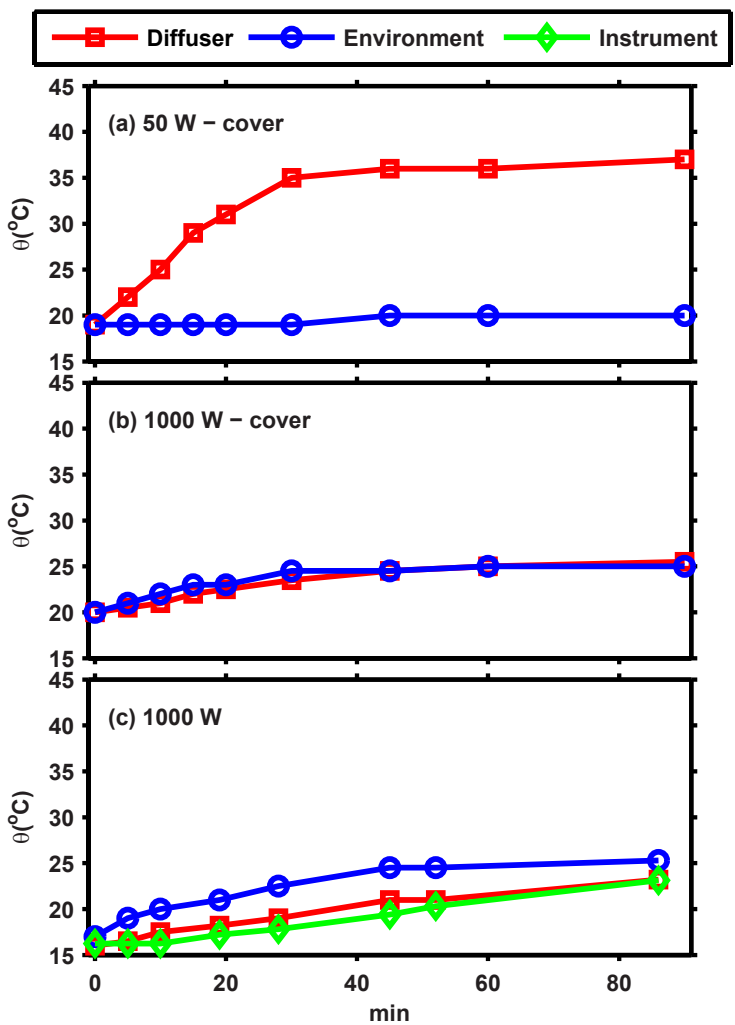

Figure 2. Change of the temperature of the diffuser of B005 (a) when a $50 \mathrm{~W}$ lamp is placed at a vertical distance of $5 \mathrm{~cm}$ above the diffuser and only the cover is used, (b) when a $1000 \mathrm{~W}$ lamp is placed at a vertical distance of $50 \mathrm{~cm}$ above the diffuser and only the cover is used, and (c) when a $1000 \mathrm{~W}$ lamp is placed at a vertical distance of $50 \mathrm{~cm}$ above the diffuser and the instrument is operating normally (the instrument is inside the cover).

For the $50 \mathrm{~W}$ lamp (Fig. 2a) the temperature of the diffuser increases fast, by about $20^{\circ} \mathrm{C}$ in the first $30 \mathrm{~min}$, and thereafter it remains relatively stable, while the ambient temperature remains almost stable. Moreover, measurements at different parts of the diffuser's surface while it was illuminated revealed inhomogeneities of $5-6^{\circ} \mathrm{C}$. These findings suggest that $50 \mathrm{~W}$ tungsten halogen lamps are not suitable to characterize the overall temperature dependence of the Brewer, since they affect the temperature and eventually the throughput of the diffuser.

For the $1000 \mathrm{~W}$ lamp, the temperature of the diffuser increases gradually by $5-8^{\circ} \mathrm{C}$ following the almost identical increase in the ambient temperature in the dark room (Fig. 2b). This suggests that the lamp does not affect significantly the temperature of the diffuser, or at least no more than it affects the ambient temperature.

For the $1000 \mathrm{~W}$ lamps we also tested an alternative configuration: the whole instrument (not only the cover) was placed under the lamp and the temperature of the diffuser was recorded by pointing the IR thermometer towards the upper surface of the diffuser after temporarily removing the quartz dome. During each measurement the radiation of the lamp was blocked. Then the dome was restored to its position and the lamp was unblocked to illuminate the diffuser until the next measurement. Each measurement (from blocking to unblocking the light) did not last more than $\sim 1 \mathrm{~min}$. During this test, in addition to the ambient temperature of the dark room, the temperature at the PMT was also recorded using a built-in thermistor. The measurements collected from this test are presented in Fig. 2c. As with the cover only, the temperature of the diffuser is not affected by the lamp's radiation and increases gradually following the increase in the temperature at the PMT. This suggests that the temperature at the PMT could represent both the internal temperature of the Brewer and that of the diffuser for the characterization procedure. However, during regular outdoors operation the temperature of the diffuser may differ significantly from the temperature of the PMT, as discussed later.

The slower increase in the diffuser's temperature compared to Fig. $2 b$ is possibly explained by the fact that the lower surface of the diffuser is not exposed to ambient air, protected by the cover and the body of the instrument. Finally, it may be concluded that the $1000 \mathrm{~W}$ lamps, or any type of lamp that is positioned adequately far from the diffuser to prevent direct heating, can be safely used to characterize the temperature response of the Brewer.

At the station of Izaña, the temperature of the diffuser of B185 was recorded using an infrared sensor while a $200 \mathrm{~W}$ lamp was placed above the diffuser. In this case the sensor was adjusted inside the instrument, aiming at the bottom surface of the diffuser, and its signal was recorded by a data logger which was also placed inside the instrument. The setup of the $200 \mathrm{~W}$ lamp is the same as that used for the regular monitoring of the instrument's stability and for the temperature characterization. The measurements were performed at the location of regular operation of B185. As for the Brewers in Thessaloniki, no significant change of the temperature of the diffuser was detected while it was illuminated by the $200 \mathrm{~W}$ lamp.

The lamps used at other sites usually have similar characteristics with those used at Thessaloniki, Sodankylä, and Izaña, and even if they are not supplied from the same manufacturer they are expected to have similar effects on the temperature of the diffuser.

\section{Characterization for the effects of temperature}

The results presented in this section were obtained by characterizing the temperature sensitivity of the instruments' response in the laboratory. Several instruments were tested following slightly different procedures according to the facilities available at each station. The temperature of the PMT which is regularly monitored has been used to derive the temperature correction factors. At Thessaloniki, the B005 and 
Table 1. Information for each Brewer spectrophotometer and the corresponding temperature characterization procedure.

\begin{tabular}{|c|c|c|c|c|}
\hline Site & $\begin{array}{l}\text { Instrument } \\
\text { (type) }\end{array}$ & $\begin{array}{l}\text { Monochromator } \\
\left(\mathrm{NiSO}_{4} \text { filter }\right)\end{array}$ & Characterization method & $\begin{array}{r}\text { Temperature } \\
\text { range }\left({ }^{\circ} \mathrm{C}\right)\end{array}$ \\
\hline Helsinki, Finland & B107 (MKIII) & Double (no) & $\begin{array}{l}\text { Laboratory measurements using } \\
1000 \mathrm{~W} \text { lamp, FMI facilities }\end{array}$ & $\sim 15-30$ \\
\hline Izaña, Tenerife, Spain & B185 (MKIII) & Double (no) & $\begin{array}{l}\text { Measurements in climate chamber } \\
\text { using } 200 \mathrm{~W} \text { lamp, PTB facilities }\end{array}$ & $\sim-5-50$ \\
\hline \multirow[t]{2}{*}{ Lindenberg, Germany } & B030 (MKIV) & Single (yes) & Measurements in climate chamber & $\sim 10-35$ \\
\hline & B078 (MKIV) & Single (yes) & using $200 \mathrm{~W}$ lamp, DWD facilities & $\sim 5-45$ \\
\hline \multirow[t]{2}{*}{ Thessaloniki, Greece } & B005 (MKII) & Single (yes) & Laboratory measurements using & $\sim 15-50$ \\
\hline & B086 (MKIII) & Double (no) & $1000 \mathrm{~W}$ lamp, LAP facilities & $\sim 15-45$ \\
\hline \multirow[t]{2}{*}{ Sodankylä, Finland } & B037 (MKII) & Single (yes) & Laboratory measurements using & $\sim 10-45$ \\
\hline & B214 (MKIII) & Double (no) & $1000 \mathrm{~W}$ lamp, FMI facilities & $\sim 10-45$ \\
\hline
\end{tabular}

B086 were moved from the site of the instruments' regular operation inside the calibration room during a cold day and irradiance measurements of a $1000 \mathrm{~W}$ lamp were performed as the room temperature and the internal temperature of the instruments were gradually increasing. The increase in temperature was slow enough to ensure that the temperatures of the room and the instrument are equilibrated (Garane et al., 2006). At Sodankylä and Helsinki, B037, B107 and B214 were also carried inside the laboratory, where irradiance measurements were performed similarly as during a calibration (Lakkala et al., 2008), but the temperature of the Brewer was slowly increased or decreased using an airblower system built for the specific purpose (Lakkala et al., 2008). Before each measurement, the temperature was stabilized and remained constant during the measurement. At Lindenberg, B030 and B078 were placed in a chamber wherein the temperature was increased or decreased slowly and scans were performed using a $200 \mathrm{~W}$ lamp after the temperatures outside and inside the instrument were fully stabilized and temperature gradients were practically zero. B185 was also placed in a chamber at the facilities of PTB and the temperature characterization was obtained similarly as for B030 and B078 (Berjón et al., 2017). In all the above cases the current of the lamps was constant within less than $1 \mathrm{~mA}$ (8 A for the $1000 \mathrm{~W}$ lamps and $6.3 \mathrm{~A}$ for the $200 \mathrm{~W}$ lamps) during measurements. The spectrum of the used lamp was measured before and after the characterization of B037, B107 and B214 to ensure that neither the response of the instruments nor the characteristics of the lamp changed during the characterization procedure. For the remaining five Brewers, the signal of the lamp was recorded using either a photodiode (B005, B086, B030 and B078) or a silicon detector and a CCD spectrometer (B185) to ensure that the detected changes are not due to changes of the lamp's emission. In all cases a line (the 297 or $302 \mathrm{~nm}$ line depending on each instrument settings) of the internal $\mathrm{Hg}$ lamp (Kipp \& Zonen, 2008) was scanned before measurements at specific temperature to ensure wavelength stability. All measured spectra were corrected for the effects of the dark signal and the dead time, and smoothed by a three-point moving average filter to suppress the noise. Finally, the change of the instrument's response with respect to temperature was calculated.

Brief information regarding the site of regular operation and the characteristics (type, single or double monochromator, $\mathrm{NiSO}_{4}$ filter or not) of each instrument is summarized in Table 1. Short descriptions of the method of characterization and the temperature range are also provided in the last two columns.

\subsection{Temperature correction factors for different Brewers}

Analysis of the measurements of the eight Brewer spectrophotometers revealed three temperature ranges (TRs) with different patterns in the temperature response: low (TR1), around $19^{\circ} \mathrm{C}(\mathrm{TR} 2)$ and high (TR3). In these ranges spectral measurements of the global UV irradiance should be treated differently in order to correct for temperature effects. In each range the temperature dependence of the instrument's response can be described to a good approximation by leastsquares linear fit. Although for each individual instrument the slopes of the linear fits change with wavelength, the limits of the temperature ranges are wavelength independent. Indicative results for $315 \mathrm{~nm}$ and for all the eight instruments are presented in Fig. 3. The limits were estimated by eye and then the linear fit that describes the change in response for each TR was calculated.

Measurements below $10^{\circ} \mathrm{C}$, which provide information for TR1, were possible only for three of the instruments (specifically for B078, B185 and B214). At this point it should be noted that Brewer spectrophotometers are equipped with a heater which is automatically turned on when the internal temperature drops below a specific limit, either 10 or $20^{\circ} \mathrm{C}$ (Kipp \& Zonen, 2008). Thus, even for ambient temperatures below zero, the internal temperature does not usually drop below 0 and $10^{\circ} \mathrm{C}$, respectively. For the same reason, it is difficult to perform measurements for such low internal temperatures during the characterization proce- 

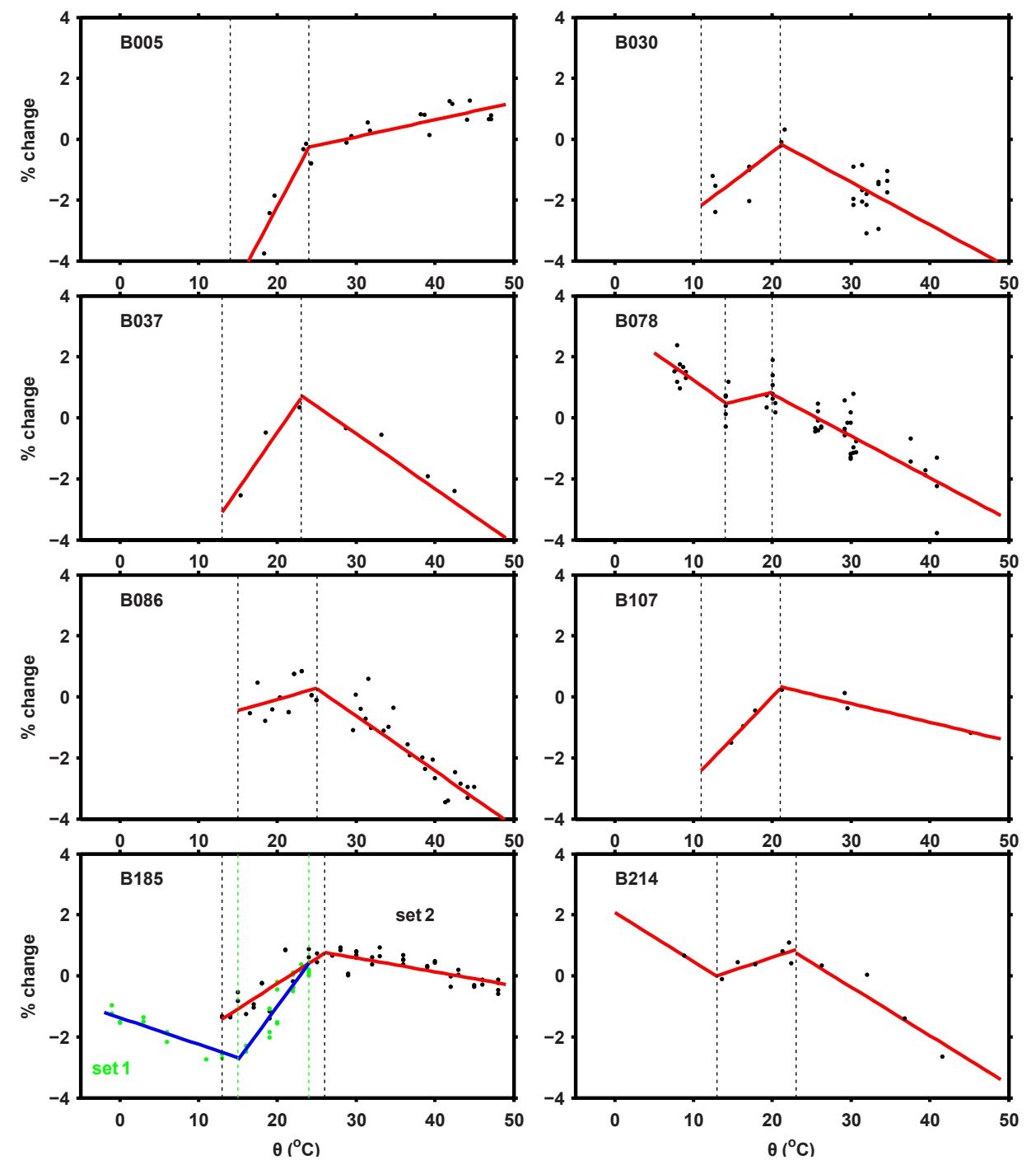

Figure 3. Change (in \%) in irradiance at $315 \mathrm{~nm}$ with respect to the instrument's internal temperature for eight Brewer spectrophotometers. The estimated limits that separate the three TRs for each instrument are represented by the two dotted lines, while the linear fits that describe the change in each instrument's response are represented by the red lines. For B185 the two sets of measurements are represented by different colors (green and black) as well as the corresponding linear fits (blue and red).

dure. For B185 and B214 the heater threshold has been set to $20^{\circ} \mathrm{C}$, while for the other six instruments it is set to $10^{\circ} \mathrm{C}$. To achieve low internal temperatures for the first two, the heaters were disconnected during the characterization procedure. For B185, two sets of measurements were performed: one for internal temperatures ranging from -2 to $24^{\circ} \mathrm{C}$ and one for temperatures between 13 and $50^{\circ} \mathrm{C}$. The measurements of the two sets were analyzed independently. Prior to analysis, the measurements were normalized to the highest common temperature of the two sets $\left(24^{\circ} \mathrm{C}\right)$. For all the other instruments the measurements were normalized to the $20-30{ }^{\circ} \mathrm{C}$ means.

The results presented in Fig. 3 verify that the response changes differently in the three TRs. However, the limits of the different TRs were not found to be the same for all instruments and even for the same instrument they may differ if the characterization is repeated under different conditions. For example, for the two sets of B185, TR2 was respectively 13 and $9{ }^{\circ} \mathrm{C}$ wide - i.e., about $4^{\circ} \mathrm{C}$ different. For B078 and B214, the TR2 was 6 and $9.5^{\circ} \mathrm{C}$ wide, respectively. For the remaining five instruments, for which it was not possible to determine clearly the boundaries of TR2, this was assumed to be $10^{\circ} \mathrm{C}$. This approximation was made since this range was found close to $\sim 10^{\circ} \mathrm{C}$ for B078, B185 and B214. The limit that separates TR1 from TR2 ranges between $12^{\circ} \mathrm{C}$ (for B214) and $16^{\circ} \mathrm{C}$ (for B078), while the limit that separates TR2 from TR3 ranges from $20^{\circ} \mathrm{C}$ (for B078) to $26^{\circ} \mathrm{C}$ (second set of B185). The differences between the TR limits and 


\begin{tabular}{|llllllll|}
\hline$\square$ & 005 & $\square$ & 037 & $\square$ & 086 & $\square$ & 185 \\
$\square$ & 030 & $\square$ & 078 & $\square$ & 107 & $\square$ & 214 \\
\hline
\end{tabular}
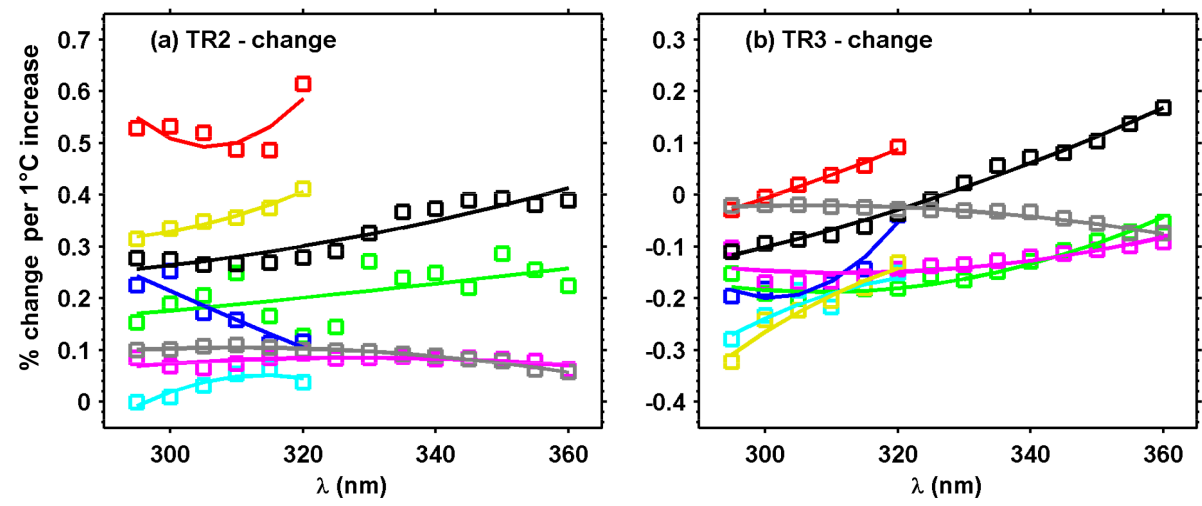

Figure 4. Change (in \%) of irradiance for $1^{\circ} \mathrm{C}$ increase in temperature as a function of wavelength for (a) TR2 and (b) TR3 for the eight Brewers.

ranges which were found for each case are estimated to be mostly related to the uncertainties in the characterization results and less to the characteristics of each instrument.

For B078, B185 and B214 the differences between the slopes of the linear fits for TR1 and TR3 are small, and although the slopes for TR1 were derived either from a limited number of measurements (B078, B214) or with the internal heater turned off, which does not represent realistic operational conditions (B185, B214), the results provide a strong indication that the slope calculated for TR3 can be also used for the correction of measurements within TR1, without inducing important errors. It is noteworthy that for seven of the eight studied cases the response is increasing in TR2 and decreasing in TR3, while increase in both TR2 and TR3 was found only for the case of B005.

In Fig. 4, the calculated slopes are presented as a function of wavelength for TR2 and TR3. For B185 only the results from the second set of measurements (for higher temperatures) are presented. For all cases the dependence from wavelength is described satisfactorily by a second-degree polynomial. With the exception of B185 (TR2 and TR3) and B030 (TR2), for all the other instruments the percentage change of their response for $1^{\circ} \mathrm{C}$ increase in temperature increases with wavelength. The dependence of the slope on wavelength is stronger for the single- compared to the doublemonochromator Brewers, possibly due to the presence of the UG11-NiSO 4 filter combination at the entrance of the PMT of the former. The change of the response in TR2 ranges from $0 \%{ }^{\circ} \mathrm{C}^{-1}$ (for B078) to $0.6 \%{ }^{\circ} \mathrm{C}^{-1}$ (for B005). In TR3 the change of the response ranges from -0.3 to $+0.2 \%$ for different instruments and wavelengths.

Analytical description of the methodology that should be used for the correction of the global UV irradiance measurements, as well as the calculated correction factors for each of the eight Brewers, can be found in the Supplement.

\subsection{The role of the diffuser}

Comparison between the patterns shown in Fig. 3 for all Brewers (i.e., decreasing, or slowly increasing, response as temperature increases for TR1, fast increasing response for TR2, and again decreasing, or slowly increasing, response for TR3) with the results of Ylianttila and Schreder (2005) leads to the conclusion that part of the observed changes is due to the effect of temperature on the transmittance of the diffuser. However, the slope of the linear fit in TR1 and TR3 is in most cases different than what would be expected according to their results, indicating that part of the dependence is due to the effect of temperature on the PMT and other internal optical and mechanical components of the instrument.

To investigate the validity of this assumption, spectral irradiance measurements were performed at different temperatures using an external lamp through the slant quartz window, and the internal SL of the Brewer. The results were then compared with those from the measurements through the diffuser. These measurements were performed by B005, B086 and B185 using slightly different setups. For all the three Brewers it was found that, while for the measurements through the diffuser the response changes differently in TR1, TR2, and TR3, for the measurements of the external lamp through the window and the SL the response changes at the same rate in the entire range of recorded temperatures. The results for B005 are presented in Fig. 5 .

In Fig. 5a, the linear fits of the results are also presented. In Fig. 5b the slopes of the least squares linear fits and the corresponding $1 \sigma$ uncertainty in their determination are presented, as well as the second-degree polynomials which describe the dependence from wavelength in each case. These results confirm that the differences in patterns found between the three TRs are mainly due to the change in the transmissivity of the Teflon diffuser. For the measurements through the window it was found that the change in the response 

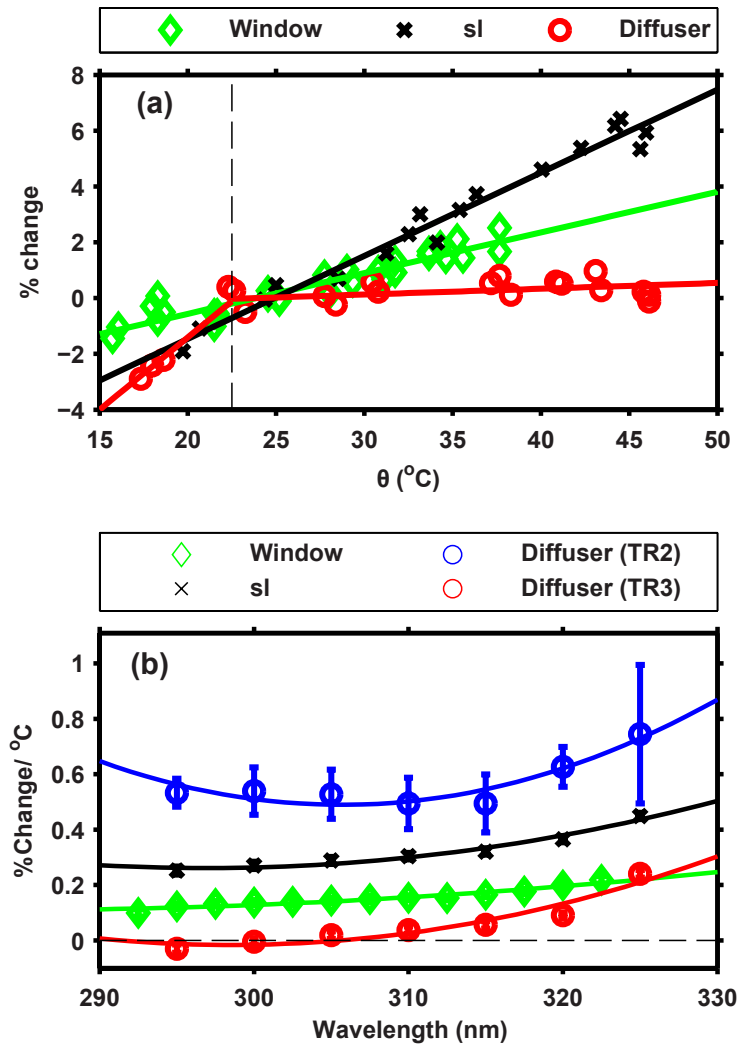

Figure 5. (a) Change in the response of B005 as a function of temperature for the SL and measurements through the window and the diffuser, relative to the response at $25^{\circ} \mathrm{C}$ and (b) the dependence of the derived slopes from wavelength.

per ${ }^{\circ} \mathrm{C}$ is wavelength dependent for both the single- and the double-monochromator Brewers, indicating that the dependence of wavelength might not be introduced solely by the $\mathrm{NiSO}_{4}$ filter used only in the single-monochromator Brewers, as suggested by Weatherhead et al. (2001) and Garane et al. (2006). Some possible explanations for the different results for the SL and the measurements through the window are the following: (a) large temperature gradients exist inside the instrument when the SL is on, (b) the electronic circuits of the SL may be affected by temperature and (c) the transmittance of the quartz window may be affected by temperature. However, further investigation is beyond the scope of the present study. In order to clarify whether the changes of temperature may also affect the transmittance of the quartz dome, spectral irradiance measurements with and without the dome were performed by B086 and the mean spectral transmittance of the dome was derived for different temperatures. It was found that for temperatures ranging between $\sim 15$ and $45^{\circ} \mathrm{C}$ the dome blocks $\sim 6 \%$ of the incoming radiation, independently of temperature or wavelength.

Ylianttila and Schreder (2005) measured the transmissivity of a number of radiometric instruments, none of which was a Brewer, and found that the effect of temperature on the transmissivity of the Teflon diffusers mainly depends on their thickness and the wavelength of the incident irradiance. For the cases they studied, they found that near $19^{\circ} \mathrm{C}$ the temperature transmissivity changes range between $\sim 1$ and $3 \%$, which is in good agreement with our results. The width of TR2 also seems to differ by a few ${ }^{\circ} \mathrm{C}$ between the different instruments used in their study. The differences between the changes of response and the width of TR2 (even when the same characterization methodology was used) for the Brewers used in this study denote that the individual characteristics of each diffuser may play an important role in its correspondence to the changes of temperature. However, part of these differences is also related to the uncertainties in the characterization procedure, as explained in the following.

\subsection{Uncertainties in the characterization and the correction}

Ideally, the characterization should be performed separately for the effect of temperature on the transmittance of the Teflon diffuser, the transmittance of the internal optical and mechanical components and the response of the PMT. However this is not possible due to insufficient information to partition the effect among the different components, as well as due to lack of systematic recording of temperature at each component. A parameterization including the PMT and the ambient (environmental) temperature might also describe more accurately (than using only the PMT temperature) the effect of temperature, since in this way the possible differences between the temperature of the PMT and the diffuser would be partially taken into account. However, this would make the characterization very complicated. Furthermore, the environmental temperature out in the sunlight, where the Brewers are routinely operating, is different from the temperature provided by the meteorological stations which is measured in the shade, with the former not usually recorded. Therefore, the characterization and correction is performed for the overall response to temperature using the temperature that is recorded by the thermistor attached to the PMT for each single spectral scan. The assumption that this temperature is representative of all parts of the instrument introduces some uncertainties, which are difficult to quantify.

\subsubsection{Temperature gradients inside the instrument}

During the characterization procedure, the 200 and $1000 \mathrm{~W}$ lamps do not warm the diffuser, and as long as the warming or cooling of the Brewer is slow, the differences between the temperature of the diffuser and the PMT can be considered negligible. However, during the regular operation of the Brewer, larger differences may exist. A suitably designed infrared sensor was installed inside B185 to record the temperature of the lower surface of the diffuser for about a month during which the instrument was operating regularly outside and the ambient temperature was ranging between 
$\sim-2$ and $27^{\circ} \mathrm{C}$. Analysis of the results revealed that when the internal heater is off, the difference is generally smaller than $4{ }^{\circ} \mathrm{C}$, showing that even large differences between the environmental and the internal temperature, which are not unusual for Brewers (Weatherhead et al., 2001), do not imply correspondingly large differences between the temperatures of the PMT and the diffuser. However, when the heater is on (below $20^{\circ} \mathrm{C}$ ), temperature gradients appear in the instrument, which become more important as the temperature decreases. Under these conditions, the temperature of the diffuser is much lower than the temperature of the PMT, and for the lowest recorded internal temperatures $\left(15-16^{\circ} \mathrm{C}\right)$ differences of up to $10^{\circ} \mathrm{C}$ can be encountered. For instruments for which the heater is turned on at $10^{\circ} \mathrm{C}$, the gradients are expected to be important at lower temperatures. Based on the results of Ylianttila and Schreder (2005) and the results presented in Fig. 3, we estimate that the errors in the correction of measurements due to the difference between the recorded and the actual temperature of the diffuser when the heater is on are, in all the studied cases, smaller than $2 \%$.

\subsubsection{Hysteresis of the PMT}

The hysteresis is not solely related to the temperature gradients inside the instrument when the heater is on. The interior of the PMT is a vacuum and heat conducts through it very slowly. Thus, the PMT reaches the temperature level of the environment later than other parts of the instrument and it is questionable whether the recordings of the thermistor which is attached to the PMT housing represents its actual temperature or the temperature of the housing. Hysteresis loops that have been also observed when measurements of the SL were analyzed with respect to temperature (for B005, B086 and B185), as well as analysis of the characterization results for high temperatures (for which the heater is turned off), confirm this assumption, although the hysteresis due to the delay in the response of the PMT is estimated to have a minor impact on the overall behavior of the instrument compared to the impact of the differences between the temperature of the diffuser and the PMT.

\subsubsection{Effect of temperature on the determination of the spectral response}

The determination of the spectral response of the Brewers is usually performed in the laboratory using $1000 \mathrm{~W}$ lamps. As shown in Fig. 2, the lamps warm the air in the calibration room, which leads to a gradual increase in the instrument's internal temperature. Depending on the instrument and the measurement settings determined by the operator, each scan of the lamp's spectrum may last from a few $(\sim 3-5)$ to several ( $\sim 20-30) \mathrm{min}$. Thus, according to the results presented in Fig. 2, the temperature of the instrument changes during each spectral scan and at the end of the scan it may differ by a few ${ }^{\circ} \mathrm{C}$. In the case of Thessaloniki the calibration room is small (a few $\mathrm{m}^{2}$ ) and the lamp warms the air in the room fast. Performing the calibration in a bigger room and/or improving the ventilation would lead to slower changes of the temperature. Obviously, the calibration factor should be derived for a standard temperature, or alternatively all measurements should be interpolated to the temperature of the calibration. For this purpose, the temperature which is recorded at the beginning of each scan of the lamp can be used. Based on the results presented in Figs. 2 and 3, we estimate that the uncertainty in the determination of the calibration factors due to the changes of temperature during the calibration procedure will be less than $\sim 0.5 \%$, given that in most cases the calibration is performed at temperatures near $25^{\circ} \mathrm{C}$ or higher, and the change of temperature during each spectral scan is less than $\sim 5^{\circ} \mathrm{C}$.

\subsubsection{Heating and cooling rate during characterization procedure}

If the rate of heating or cooling during the characterization procedure is not slow enough, non-negligible temperature gradients may appear inside the instruments. Thus slightly different heating or cooling rates during the characterization procedure may lead to the calculation of slightly different correction factors. This may explain the differences between the two sets of measurements with B185 as well as the large spread in the measurements of B030 and B078 shown in Fig. 3.

\subsubsection{Photon noise}

When the signal of the lamp is low, the uncertainty in the measurements, and consequently in the characterization results, due to the photon noise may be also important (e.g., Grajnar et al., 2008). In these cases, increase in the exposure time of the PMT may improve the results. For example, the measurements for the characterization of B005 were initially performed with an exposure time of $\sim 0.45 \mathrm{~s}$ (the results are not presented in this study) and then were repeated with an exposure time of $\sim 4.5 \mathrm{~s}$ (results presented in Figs. 3 and 4). Although the number of data points was similar in the two cases, the standard deviation in the correction factors was $\sim 10$ times larger when the exposure time was smaller. These uncertainties are generally more important at lower wavelengths where the signal of the lamp is weaker.

\subsubsection{Effect of temperature on the wavelength stability}

One more possible factor of uncertainty in the characterization procedure is the apparent responsivity change due to the effect of temperature on the wavelength stability of the instrument. Temperature changes lead to change of the instrument's spectral characteristics (Gröbner et al., 1998). To compensate for this effect, the 297 (or 302) nm line of the internal $\mathrm{Hg}$ lamp is scanned when the temperature changes by $\sim 1-2{ }^{\circ} \mathrm{C}$, and the zero position of the micrometer is adjusted 
properly (Grajnar et al., 2008). However, the correction based on the results for 297 or $302 \mathrm{~nm}$ does not ensure that there are no wavelength shifts at larger wavelengths. Spectra of the global solar irradiance measured by B005 and B086 were analyzed using the SHICrivm algorithm (Slaper et al., 1995) and no significant dependence of the wavelength shift from temperature was found. However, even if we assume a small shift in wavelength (i.e., of $0.01 \mathrm{~nm}$ ) during the characterization procedure, this would induce an important apparent responsivity change (of the order of $1 \%$ ) only for the singlemonochromator Brewers near $325 \mathrm{~nm}$ where the spectral response of the instrument changes fast.

\subsubsection{Number of spectra during characterization}

The low number of measurements also increases the uncertainty in the characterization results, especially when the recorded signal and the exposure time of the PMT are also low. The finite, usually low number of measurements in the TR1 and TR2 induce uncertainties in the determination of the TR limits and the correction factors. Thus, for each instrument, slightly different TR1-TR2 and TR2-TR3 limits may be found when the characterization is repeated. Analysis of the characterization results for four different sets of measurements (performed in different days of 2005) with B086 resulted in TR2-TR3 limits ranging between 24 and $28^{\circ} \mathrm{C}$. The same analysis for B005 resulted in smaller differences $\left(22-24^{\circ} \mathrm{C}\right)$. Separate analysis of the results for the warming and the cooling of B185, for the second set of measurements, also lead to different TR2-TR3 limits, at $\sim 30$ and $\sim 23^{\circ} \mathrm{C}$, respectively. We estimate that the uncertainties in the correction factors due to these differences cannot exceed $\pm 0.5 \%$.

\subsection{Evaluation of the derived correction factors}

For the evaluation of the results presented in Sect. 3.1, global UV spectra that were measured nearly simultaneously by the two Brewer spectrophotometers operating at Thessaloniki (B005 and B086) and by those operating at Sodankylä (B037 and B214) were compared to each other. For Thessaloniki, measurements for 15 years (2001-2014) were used in the comparison, while for Sodankylä measurements were available only for a period of 6 months (April-October 2016). More specifically, the $300-325 \mathrm{~nm}$ integrals of spectra measured within $1 \mathrm{~min}$ were compared for each pair of collocated instruments, before and after applying the temperature correction. Since changes in temperature affect the measurements of each instrument differently, it is expected that the ratio of the uncorrected for the effect of temperature data between two instruments will be temperature dependent, and that the greatest part of this dependence would be eliminated when temperature-corrected data are used instead. These ratios normalized to the mean ratio at $25^{\circ} \mathrm{C}$ are shown in Fig. 6 for Thessaloniki and Sodankylä Brewers as a function of temperature recorded, respectively, by B086 and B037. The error bars represent the $1 \sigma$ standard deviation of the mean for each $10^{\circ} \mathrm{C}$ bin.

According to Fig. 6a, the temperature correction of the data of B005 and B086 almost eliminates the otherwise strong temperature dependence of their ratio. Similar results are achieved for the two Brewers operating in Sodankylä. Despite the lower temperatures in Sodankylä, which may result in large temperature gradients inside each instrument when the heaters are turned on, the results verify that the applied correction is towards the right direction, even for ambient temperatures of about $-10^{\circ} \mathrm{C}$.

Temperature correction factors were determined for B005 and B086 operating in Thessaloniki twice, in 2005 (Garane et al., 2006) and 2015. The differences in the derived temperature correction factors are smaller than their $1 \sigma$ uncertainty, suggesting that these correction factors are valid for the entire period (2001-2015). This has also been confirmed by the comparison of quasi-simultaneous measurements of the two instruments for this period. In contrast, the comparison of measurements for the period 1993-2000 revealed that the correction factors cannot remove effectively the dependence effects for this period. This can be attributed to the replacement of the PMT of B086 in 2000, which has different temperature response compared to the old PMT. Replacement of other electronic parts of B005 and B086 was not found to induce detectable changes in their behavior regarding the effects of temperature. The above indicate that the temperature dependence does not change significantly with time, as long as the components of the instrument that are mainly affected by changes in temperature (i.e., the Teflon diffuser and the PMT) remain the same.

\section{Conclusions}

The sensitivity of the Brewer spectrophotometers in spectral irradiance measurements shows a marked dependence to temperature variations. Thus, the use of uncorrected spectra for the study of the diurnal, seasonal and annual changes of UV irradiance would lead to inaccurate results due to the corresponding cycles of temperature. Although improper correction of the spectra for the effects of temperature would not possibly have an important effect on the study of the longterm changes of the UV irradiance at low and mid-latitudes, it may be more important for higher latitudes where the annual mean temperature is changing, and is projected to keep changing fast in the following decades (IPCC, 2007). Accurate correction of the spectra for the effects of temperature would improve the agreement between the measurements from different Brewers and lead to a more reliable product which in turn would be suitable for climatological studies and the validation of satellite products and model simulations.

The $\%$ difference of the $315 \mathrm{~nm}$ response from its value at $25^{\circ} \mathrm{C}$ due to the effect of temperature is presented in Fig. 7 


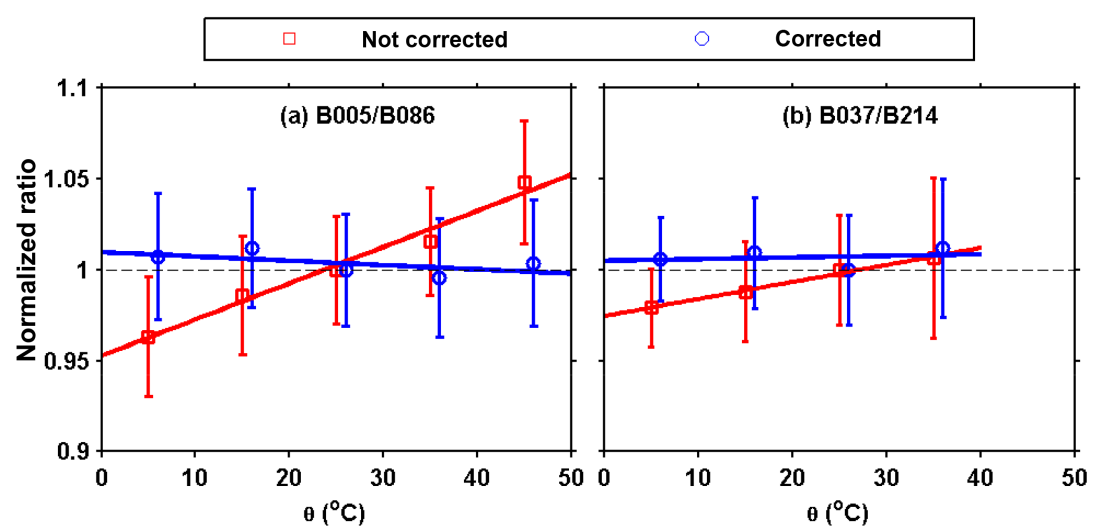

Figure 6. Ratio of the 300-325 nm irradiance integrals derived for each pair of Brewers as a function of temperature before and after applying a temperature correction for (a) B005 and B086 in Thessaloniki and (b) B037 and B214 in Sodankylä. The ratios have been normalized to the mean ratio at $25^{\circ} \mathrm{C}$. The error bars represent the $1 \sigma$ standard deviation of the mean for each $10^{\circ} \mathrm{C}$ bin.
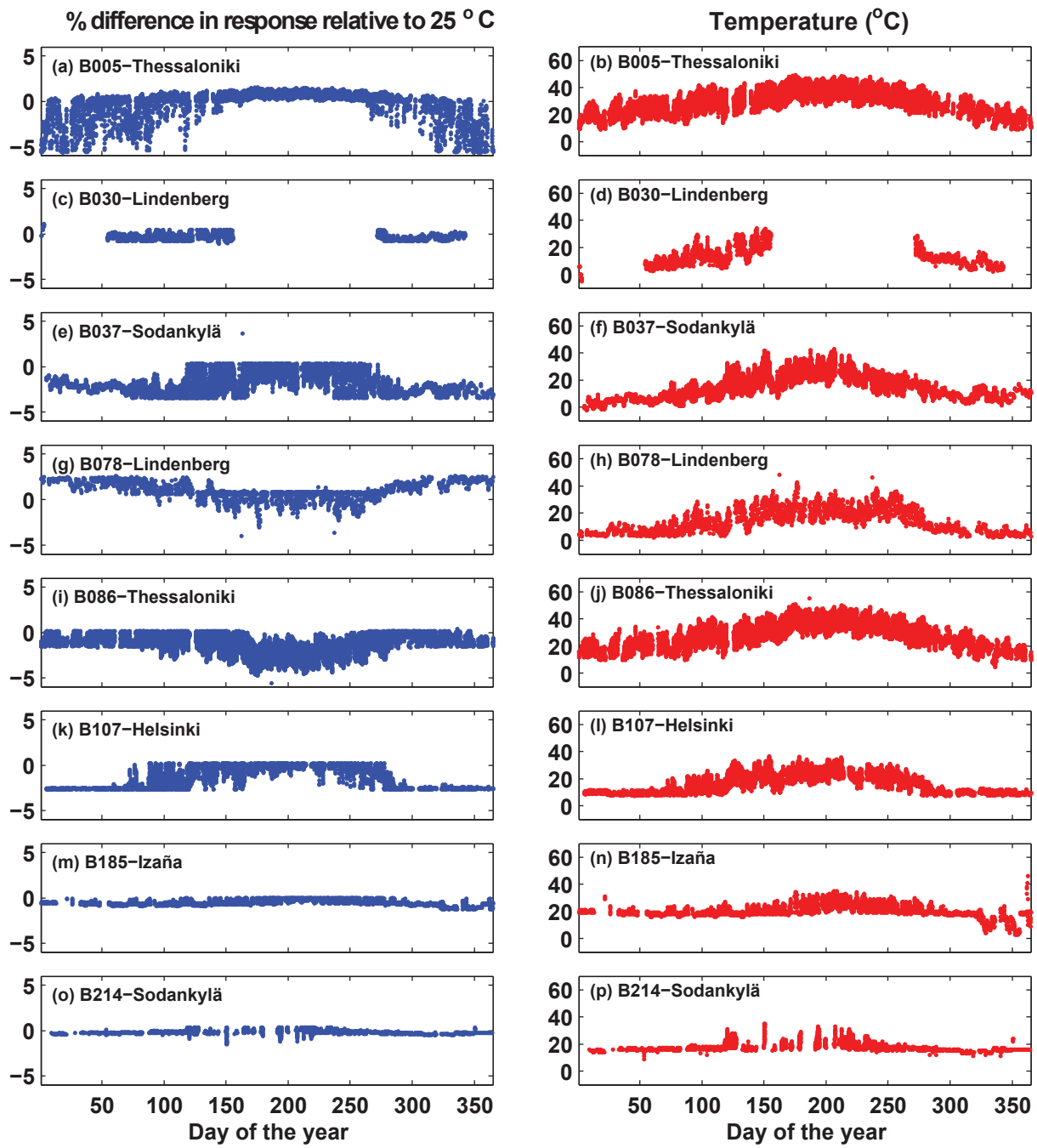

Figure 7. Differences (\%) in the $315 \mathrm{~nm}$ response from its value at $25^{\circ} \mathrm{C}$ due to the effect of temperature and the corresponding temperatures. 
(left column). The presented results are for all the spectra measured in 2016 and for all the eight Brewers used in this study. The corresponding temperatures recorded at the PMT are presented in the right column of the same figure. The differences from the response at $25^{\circ} \mathrm{C}$ have been calculated using the results of Sect. 3.1.

Depending on the site and the instrument, the response may differ by up to $6 \%$ (e.g., in the case of B005) in a year. These differences seem to be smaller (occasionally of the order of $1.5 \%$ in a day) for instruments which operate at low temperatures and the threshold of the heater is $20^{\circ} \mathrm{C}$ (e.g., B185 and B214). However, as explained earlier, the correction of the measurements from these instruments is more uncertain due to the large temperature gradients when the heater is on. According to the results presented in Fig. 7, there are upper and/or lower limits in the changes of the response for most Brewers. These limits correspond to the turning points (limits between TR 1 and TR 2 and between TR2 and TR 3 ) of the lines presented in Fig. 3 and are evident because for all studied cases the temperature ranges between a lower (between 0 and $20^{\circ} \mathrm{C}$ ) and an upper (between 30 and $50^{\circ} \mathrm{C}$ ) limit.

The temperature response of Brewers, whether single or double monochromators, is wavelength dependent and instrument specific. The main components of the Brewer spectrophotometers that determine their behavior relative to temperature variations are the PMT, the diffuser and possibly the UG11-NiSO 4 filter in the single-monochromator Brewers.

For irradiance measurements through the Teflon diffuser (global irradiance) the response is not unique for the entire range of operating temperatures, mainly because of the steep increase (decrease) in the transmissivity of the diffuser as the temperature increases (decreases) from $\sim 12$ (22) to $22(12)^{\circ} \mathrm{C}$. It is suggested that different correction factors should be used for three different temperature ranges (TR1: below $\sim 12{ }^{\circ} \mathrm{C}$; TR2: $\sim 12-22^{\circ} \mathrm{C}$; TR3: above $\left.\sim 22^{\circ} \mathrm{C}\right)$. The temperature dependence is very similar in TR1 and TR3; thus, applying the same correction factors for these ranges does not introduce large uncertainties.

Characterization for the effects of temperature using the $50 \mathrm{~W}$ lamps, which are operationally used to monitor the stability of the Brewer spectrophotometers, may lead to wrong correction factors since these lamps are positioned very close to the diffuser, increase its temperature and alter its transmissivity. The $1000 \mathrm{~W}$ lamps, regularly used for the absolute irradiance calibration at distances longer than $50 \mathrm{~cm}$, do not heat the diffuser and lead to more reliable results when they are used for the temperature characterization. The setup with $200 \mathrm{~W}$ lamps, which is used at several stations for monitoring the instruments' stability, is also suitable for temperature characterization because the distance of the lamp from the diffuser is adequately long to prevent direct heating.

The proposed methodology, which is described in detail in the Supplement, was evaluated using spectra from the Brewer spectrophotometers operating at Thessaloniki and Sodankylä and was found to remove the greatest part of the temperature dependence from the irradiance measurements. The correction of the spectra using the specific methodology is more accurate compared to the correction based on the methodologies described in previous studies (Garane et al., 2006; Lakkala et al., 2008; Siani et al., 2003; Weatherhead et al., 2001), since the effect of temperature on the transmissivity of the diffuser is also taken into account. The correction factors for each Brewer depend on its individual constructional characteristics; thus it is not possible to apply generic correction for all Brewer spectrophotometers and characterization of each individual instrument is necessary. Repeating the characterization procedure frequently was not found necessary, as long as the main components of the instrument which are affected by temperature variations are not replaced.

The uncertainties in the calculated correction factors are small, as long as the warming and cooling of the instrument is slow enough to prevent the development of large temperature gradients inside the instrument during the characterization procedure. Increasing the number of measured spectra and/or the exposure time of the PMT, especially at temperatures between $\sim 10$ and $25^{\circ} \mathrm{C}$, may lead to smaller uncertainties in the derived correction factors. Uncertainties in the correction of global irradiance spectra arise mainly from the use of the temperature recorded at the PMT to correct the measurements. Large temperature gradients inside the instrument when the heater is turned on, may occasionally lead to large differences, of the order of $10^{\circ} \mathrm{C}$, between the actual temperatures of the PMT and the diffuser. For particular instruments, these differences may subsequently lead to errors of up to $2 \%$ in the correction of spectra recorded with the heater on. The uncertainties due to the characterization procedure and the methodology to derive the correction factors are estimated to be generally smaller than $0.5 \%$ and more important for temperatures below $\sim 25^{\circ} \mathrm{C}$.

Data availability. The data used for the present study can be made available after personal communication with the authors of the present paper.

\section{The Supplement related to this article is available online at https://doi.org/10.5194/amt-10-4491-2017-supplement.}

Competing interests. The authors declare that they have no conflict of interest.

Special issue statement. This article is part of the special issue "Quadrennial Ozone Symposium 2016 - Status and trends of atmospheric ozone (ACP/AMT inter-journal SI)". It is a result of the Quadrennial Ozone Symposium 2016, Edinburgh, UK, 49 September 2016. 
Acknowledgements. This article is based upon work from COST Action ES1207 "A European Brewer Network (EUBREWNET)", supported by COST (European Cooperation in Science and Technology) and from the ENV59-ATMOZ ("Traceability for atmospheric total column ozone") Joint Research Programme (JRP). The JRP is jointly funded by the EMRP participating countries within EURAMET and the European Union. All the members of the COST Action ES1207 who contributed, either by providing data which were finally not used in the present study or through constructive discussions, are also acknowledged. Special thanks to Julian Gröbner for his helpful advice. The anonymous reviewers are also acknowledged for their constructive reviews that helped improve the quality of this paper.

Edited by: Wolfgang Steinbrecht

Reviewed by: three anonymous referees

\section{References}

Antón, M., Serrano, A., Cancillo, M. L., Vilaplana, J., Cachorro, V. E., and Gröbner, J.: Correction of Angular Response Error in Brewer UV Irradiance Measurements, J. Atmos. Ocean. Tech., 25, 2018-2027, https://doi.org/10.1175/2008jtecha1040.1, 2008.

Arola, A., Kalliskota, S., den Outer, P. N., Edvardsen, K., Hansen, G., Koskela, T., Martin, T. J., Matthijsen, J., Meerkoetter, R., Peeters, P., Seckmeyer, G., Simon, P. C., Slaper, H., Taalas, P., and Verdebout, J.: Assessment of four methods to estimate surface UV radiation using satellite data, by comparison with ground measurements from four stations in Europe, J. Geophys. Res.-Atmos., 107, ACL 11-1-ACL 11-11, https://doi.org/10.1029/2001JD000462, 2002.

Arola, A., Lakkala, K., Bais, A., Kaurola, J., Meleti, C., and Taalas, P.: Factors affecting short- and long-term changes of spectral UV irradiance at two European stations, J. Geophys. Res.-Atmos., 108, https://doi.org/10.1029/2003jd003447, 2003.

Bais, A. F., Zerefos, C. S., Meleti, C., Ziomas, I. C., and Tourpali, K.: Spectral measurements of solar UVB radiation and its relations to total ozone, $\mathrm{SO}_{2}$, and clouds, J. Geophys. Res.-Atmos., 98, 5199-5204, https://doi.org/10.1029/92jd02904, 1993.

Bais, A. F., Zerefos, C. S., and McElroy, C. T.: Solar UVB measurements with the double- and single-monochromator Brewer ozone spectrophotometers, Geophys. Res. Lett., 23, 833-836, https://doi.org/10.1029/96gl00842, 1996.

Bais, A. F., Kazadzis, S., Balis, D., Zerefos, C. S., and Blumthaler, M.: Correcting global solar ultraviolet spectra recorded by a Brewer spectroradiometer for its angular response error, Appl. Optics, 37, 6339-6344, https://doi.org/10.1364/ao.37.006339, 1998.

Berjón, A., Redondas, A., Sildoja, M.-M., Nevas, S., Wilson, K., León-Luis, S. F., El Gawhary, O., and Fountoulakis, I.: Characterization of the instrument temperature dependence of Brewer total ozone column measurements, Atmos. Meas. Tech. Discuss., https://doi.org/10.5194/amt-2017-406, in review, 2017.

Bernhard, G. and Seckmeyer, G.: Uncertainty of measurements of spectral solar UV irradiance, J. Geophys. Res.-Atmos., 104, 14321-14345, https://doi.org/10.1029/1999jd900180, 1999.

Bernhard, G., Booth, C. R., Ehramjian, J. C., Stone, R., and Dutton, E. G.: Ultraviolet and visible radiation at Barrow, Alaska: Clima- tology and influencing factors on the basis of version 2 National Science Foundation network data, J. Geophys. Res.-Atmos., 112, D09101, https://doi.org/10.1029/2006jd007865, 2007.

Bernhard, G., McKenzie, R. L., Kotkamp, M., Wood, S., Booth, C. R., Ehramjian, J. C., Johnston, P., and Nichol, S. E.: Comparison of ultraviolet spectroradiometers in Antarctica, J. Geophys. Res.-Atmos., 113, D14310, https://doi.org/10.1029/2007jd009489, 2008.

Bernhard, G., Arola, A., Dahlback, A., Fioletov, V., Heikkilä, A., Johnsen, B., Koskela, T., Lakkala, K., Svendby, T., and Tamminen, J.: Comparison of OMI UV observations with ground-based measurements at high northern latitudes, Atmos. Chem. Phys., 15, 7391-7412, https://doi.org/10.5194/acp-157391-2015, 2015.

Brewer, A. W.: A replacement for the Dobson spectrophotometer?, Pure Appl. Geophys., 106-108, 919-927, https://doi.org/10.1007/bf00881042, 1973.

Cappellani, F. and Kochler, C.: Temperature effects correction in a Brewer MKIV spectrophotometer for solar UV measurements, J. Geophys. Res.-Atmos., 105, 4829-4831, https://doi.org/10.1029/1999jd900254, 2000.

De Bock, V., De Backer, H., Van Malderen, R., Mangold, A., and Delcloo, A.: Relations between erythemal UV dose, global solar radiation, total ozone column and aerosol optical depth at Uccle, Belgium, Atmos. Chem. Phys., 14, 12251-12270, https://doi.org/10.5194/acp-14-12251-2014, 2014.

Fioletov, V. E., Griffioen, E., Kerr, J. B., Wardle, D. I., and Uchino, O.: Influence of volcanic sulfur dioxide on spectral UV irradiance as measured by Brewer Spectrophotometers, Geophys. Res. Lett., 25, 1665-1668, https://doi.org/10.1029/98gl51305, 1998.

Fioletov, V. E., McArthur, L. J. B., Kerr, J. B., and Wardle, D. I.: Long-term variations of UV-B irradiance over Canada estimated from Brewer observations and derived from ozone and pyranometer measurements, J. Geophys. Res.-Atmos., 106, 2300923027, https://doi.org/10.1029/2001jd000367, 2001.

Fioletov, V. E., Kerr, J. B., McArthur, L. J. B., Wardle, D. I., and Mathews, T. W.: Estimating UV Index Climatology over Canada, J. Appl. Meteorol., 42, 417-433, https://doi.org/10.1175/15200450(2003)042<0417:euicoc>2.0.co;2, 2003.

Fioletov, V. E., McArthur, L. J. B., Mathews, T. W., and Marrett, L.: On the relationship between erythemal and vitamin $\mathrm{D}$ action spectrum weighted ultraviolet radiation, J. Photoch. Photobio.y B, 95, 9-16, https://doi.org/10.1016/j.jphotobiol.2008.11.014, 2009.

Fountoulakis, I., Bais, A. F., Fragkos, K., Meleti, C., Tourpali, K., and Zempila, M. M.: Short- and long-term variability of spectral solar UV irradiance at Thessaloniki, Greece: effects of changes in aerosols, total ozone and clouds, Atmos. Chem. Phys., 16, 2493 2505, https://doi.org/10.5194/acp-16-2493-2016, 2016a.

Fountoulakis, I., Redondas, A., Bais, A. F., Rodriguez-Franco, J. J., Fragkos, K., and Cede, A.: Dead time effect on the Brewer measurements: correction and estimated uncertainties, Atmos. Meas. Tech., 9, 1799-1816, https://doi.org/10.5194/amt-9-1799-2016, $2016 b$.

Fragkos, K., Bais, A., Fountoulakis, I., Balis, D., Tourpali, K., Meleti, C., and Zanis, P.: Extreme total column ozone events and effects on UV solar radiation at Thessaloniki, Greece, Theor. Appl. Climatol., 126, 505-517, https://doi.org/10.1007/s00704015-1562-3, 2016. 
Garane, K., Bais, A. F., Kazadzis, S., Kazantzidis, A., and Meleti, C.: Monitoring of UV spectral irradiance at Thessaloniki (19902005): data re-evaluation and quality control, Ann. Geophys., 24, 3215-3228, https://doi.org/10.5194/angeo-24-3215-2006, 2006.

Grajnar, T., Savastiouk, V., and McElroy, T.: Standard operating procedures manual for the Brewer spectrophotometer, available at: http://woudc.org/archive/Documentation/SOP_ Documents/brewerspectrophotometer_sop-june2008.pdf (last access: 19 June 2017), 2008.

Gröbner, J., Wardle, D. I., McElroy, C. T., and Kerr, J. B.: Investigation of the wavelength accuracy of Brewer spectrophotometers, Appl. Optics, 37, 8352-8360, https://doi.org/10.1364/ao.37.008352, 1998.

Gröbner, J., Blumthaler, M., Kazadzis, S., Bais, A., Webb, A., Schreder, J., Seckmeyer, G., and Rembges, D.: Quality assurance of spectral solar UV measurements: results from $25 \mathrm{UV}$ monitoring sites in Europe, 2002 to 2004, Metrologia, 43, S66, https://doi.org/10.1088/0026-1394/43/2/S14, 2006.

Heikkilä, A., Sakari Mäkelä, J., Lakkala, K., Meinander, O., Kaurola, J., Koskela, T., Karhu, J. M., Karppinen, T., Kyrö, E., and de Leeuw, G.: In search of traceability: two decades of calibrated Brewer UV measurements in Sodankylä and Jokioinen, Geosci. Instrum. Method. Data Syst., 5, 531-540, https://doi.org/10.5194/gi-5-531-2016, 2016.

IPCC: Climate Change 2007: The Physical Science Basis. Contribution of Working Group I to the Fourth Assessment Report of the Intergovernmental Panel on Climate Change, edited by: Solomon, S., Qin, D., Manning, M., Chen, Z., Marquis, M., Averyt, K. B., Tignor, M., and Miller, H. L., Tech. rep., Cambridge University Press, Cambridge, UK and New York, NY, USA, 2007.

Karppinen, T., Redondas, A., García, R. D., Lakkala, K., McElroy, C. T., and Kyrö, E.: Compensating for the Effects of Stray Light in Single-Monochromator Brewer Spectrophotometer Ozone Retrieval, Atmos. Ocean, 53, 66-73, https://doi.org/10.1080/07055900.2013.871499, 2014.

Kazadzis, S., Bais, A., Arola, A., Krotkov, N., Kouremeti, N., and Meleti, C.: Ozone Monitoring Instrument spectral UV irradiance products: comparison with ground based measurements at an urban environment, Atmos. Chem. Phys., 9, 585-594, https://doi.org/10.5194/acp-9-585-2009, 2009.

Kazantzidis, A., Balis, D. S., Bais, A. F., Kazadzis, S., Galani, E., Kosmidis, E., and Blumthaler, M.: Comparison of Model Calculations with Spectral UV Measurements during the SUSPEN Campaign: The Effect of Aerosols, J. Atmos. Sci., 58, 1529-1539, https://doi.org/10.1175/15200469(2001)058<1529:comcws>2.0.co;2, 2001.

Kerr, J.: The Brewer Spectrophotometer, chap. 6, Springer Berlin Heidelberg, 160-191, https://doi.org/10.1007/978-3-642-033131_6, 2010.

Kerr, J. B. and McElroy, C. T.: Evidence for Large Upward Trends of Ultraviolet-B Radiation Linked to Ozone Depletion, Science, 262, 1032-1034, https://doi.org/10.1126/science.262.5136.1032, 1993.

Kerr, J. B. and McElroy, C. T.: Total ozone measurements made with the Brewer ozone spectrophotometer during STOIC 1989, J. Geophys. Res.-Atmos., 100, 9225-9230, https://doi.org/10.1029/94jd02147, 1995.
Kerr, J. B., Evans, W. F. J., and Asbridge, I. A.: Recalibration of Dobson Field Spectrophotometers with a Travelling Brewer Spectrophotometer Standard, chap. 77, Springer Netherlands, 381-386, https://doi.org/10.1007/978-94-009-5313-0_77, 1985a.

Kerr, J. B., McElroy, C. T., Wardle, D. I., Olafson, R. A., and Evans, W. F. J.: The Automated Brewer Spectrophotometer, chap. 80, Springer Netherlands, 396-401, https://doi.org/10.1007/978-94009-5313-0_80, 1985b.

Kimlin, M. G.: The climatology of Vitamin D producing ultraviolet radiation over the United States, J. Steroid Biochem., 89, 479483, https://doi.org/10.1016/j.jsbmb.2004.03.111, 2004.

Kipp \& Zonen: Brewer MKIII Spectrophotometer Operators Manual. Kipp \& Zonen Inc., Delft, the Netherlands, 2008.

Lakkala, K., Kyrö, E., and Turunen, T.: Spectral UV Measurements at Sodankylä during 1990-2001, J. Geophys. Res.-Atmos., 108, 4621, https://doi.org/10.1029/2002jd003300, 2003.

Lakkala, K., Arola, A., Heikkilä, A., Kaurola, J., Koskela, T., Kyrö, E., Lindfors, A., Meinander, O., Tanskanen, A., Gröbner, J., and Hülsen, G.: Quality assurance of the Brewer spectral UV measurements in Finland, Atmos. Chem. Phys., 8, 3369-3383, https://doi.org/10.5194/acp-8-3369-2008, 2008.

Lakkala, K., Heikkilä, A., Kärhä, P., Ialongo, I., Karppinen, T., Karhu, J. M., Lindfors, A. V., and Meinander, O.: 25 years of spectral UV measurements at Sodankylä, AIP Conf. Proc., 1810, 110006, https://doi.org/10.1063/1.4975568, 2017.

Mayer, B., Seckmeyer, G., and Kylling, A.: Systematic longterm comparison of spectral UV measurements and UVSPEC modeling results, J. Geophys. Res.-Atmos., 102, 8755-8767, https://doi.org/10.1029/97jd00240, 1997.

McKenzie, R., Connor, B., and Bodeker, G.: Increased Summertime UV Radiation in New Zealand in Response to Ozone Loss, Science, 285, 1709-1711, https://doi.org/10.1126/science.285.5434.1709, 1999.

Savastiouk, V.: Improvements to the direct-sun ozone observations taken with the Brewer spectrophotometer, $\mathrm{PhD}$ thesis, York University, Toronto, Ontario, Canada, 2005.

SCI-TEC Instruments Inc.: Brewer MkII Spectrophotometer, operator's manual., SCI-TEC Instruments Inc, Saskatoon, Saskatchewan, Canada, 1999.

Seckmeyer, G., Bais, A., Bernhard, G., Blumthaler, M., Booth, C. R., Disterhoft, P., Eriksen, P., McKenzie, R. L., Miyauchi, M., and Roy, C.: Instruments to measure solar ultraviolet irradiance. Part 1: Spectral instruments, World Meteorological Organization, Global Atmospheric Watch, Report No. 125, 30 pp., Tech. rep., Geneve, Switzerland, 2001.

Siani, A. M., Benevento, G., and Casale, G. R.: Temperature dependence of Brewer UV measurements at Rome station, in: Proc. SPIE 5156, Ultraviolet Ground- and Spacebased Measurements, Models, and Effects III,5156, 355-366, https://doi.org/10.1117/12.505389, 2003.

Simic, S., Fitzka, M., Schmalwieser, A., Weihs, P., and Hadzimustafic, J.: Factors affecting UV irradiance at selected wavelengths at Hoher Sonnblick, Atmos. Res., 101, 869-878, https://doi.org/10.1016/j.atmosres.2011.05.022, 2011.

Slaper, H., Reinen, H. A. J. M., Blumthaler, M., Huber, M., and Kuik, F.: Comparing ground-level spectrally resolved solar UV measurements using various instruments: A technique resolving 
effects of wavelength shift and slit width, Geophys. Res. Lett., 22, 2721-2724, https://doi.org/10.1029/95g102824, 1995.

Smedley, A. R. D., Rimmer, J. S., Moore, D., Toumi, R., and Webb, A. R.: Total ozone and surface UV trends in the United Kingdom: 1979-2008, Int. J. Climatol., 32, 338-346, https://doi.org/10.1002/joc.2275, 2012.

Weatherhead, E., Theisen, D., Stevermer, A., Enagonio, J., Rabinovitch, B., Disterhoft, P., Lantz, K., Meltzer, R., Sabburg, J., DeLuisi, J., Rives, J., and Shreffler, J.: Temperature dependence of the Brewer ultraviolet data, J. Geophys. Res.-Atmos., 106, 34121-34129, https://doi.org/10.1029/2001jd000625, 2001.

Weatherhead, E. C., Reinsel, G. C., Tiao, G. C., Meng, X.-L., Choi, D., Cheang, W.-K., Keller, T., DeLuisi, J., Wuebbles, D. J., Kerr, J. B., Miller, A. J., Oltmans, S. J., and Frederick, J. E.: Factors affecting the detection of trends: Statistical considerations and applications to environmental data, J. Geophys. Res.-Atmos., 103, 17149-17161, https://doi.org/10.1029/98jd00995, 1998.
Ylianttila, L. and Schreder, J.: Temperature effects of PTFE diffusers, Opt. Mater., 27, 1811-1814, https://doi.org/10.1016/j.optmat.2004.11.008, 2005.

Zerefos, C. S., Tourpali, K., Eleftheratos, K., Kazadzis, S., Meleti, C., Feister, U., Koskela, T., and Heikkilä, A.: Evidence of a possible turning point in solar UV-B over Canada, Europe and Japan, Atmos. Chem. Phys., 12, 2469-2477, https://doi.org/10.5194/acp-12-2469-2012, 2012. 